\title{
Probing Pseudopolymorphic Transitions in Pharmaceutical Solids using Raman Spectroscopy: Hydration and Dehydration of Theophylline
}

\author{
ANA M. AMADO, ${ }^{1}$ MARIELA M. NOLASCO, ${ }^{2}$ PAUlO J.A. RIBEIRO-CLARO ${ }^{2}$ \\ ${ }^{1}$ Química-Física Molecular, Departamento de Química, FCTUC, Universidade de Coimbra, P-3004-535 Coimbra, Portugal \\ ${ }^{2}$ CICECO-Departamento de Química, Universidade de Aveiro, P-3810-193 Aveiro, Portugal
}

Received 19 August 2006; revised 21 September 2006; accepted 24 October 2006

Published online in Wiley InterScience (www.interscience.wiley.com). DOI 10.1002 /jps.20923

\begin{abstract}
Theophylline is known to undergo vapor phase induced hydrate-anhydrate pseudopolymorphic transformations, which can affect its bioavailability. In this work, the kinetics of the pseudopolymorphic transitions of theophylline crystals in different storage conditions is studied using a vibrational spectroscopic technique. While the hydration is a single-step process with a half-life time of $c a .5 \mathrm{~h}$, the dehydration occurs through a two-step mechanism. In addition, the phase stability of hydrate-anhydrate systems in different relative humidity $(\mathrm{RH})$ conditions was probed. The critical $\mathrm{RH}$ for anhydrous teophylline was found to be at ca. $79 \%$, while the critical $\mathrm{RH}$ for dehydration is ca. 30\%. () 2007 Wiley-Liss, Inc. and the American Pharmacists Association J Pharm Sci 96:1366-1379, 2007
\end{abstract}

Keywords: Raman spectroscopy; hydrates/solvates; hydration/dehydration; water in solids; relative humidity; physical stability; kinetics; intermolecular interactions

\section{INTRODUCTION}

Pharmaceutical companies have experienced market shortages as unpredicted changes in polymorphic and pseudopolymorphic (solvates and hydrates) forms of the drugs have been observed, which ultimately affect the quality release and stability testing of finishing dosage forms. A well-known example of this problematic quality-activity relationship of a final dosage form is the case of Norvir ${ }^{\circledR}$ brand of ritonavir semisolid capsules. ${ }^{1-4}$ Commercial start-up of the drug as a semisolid capsule formulation began in

This article contains supplementary material, available at www.interscience.wiley.com/jpages/0022-3549/suppmat.

Abbreviations used: TP, TPa, TPh and TPm, theophylline and theophylline forms (anhydrous, hydrated, and metastable)

Correspondence to: Paulo J.A. Ribeiro-Claro (Telephone: +351-234-370-729; Fax: +351-234-370-084;

E-mail: mnolasco@dq.ua.pt,pclaro@dq.ua.pt)

Journal of Pharmaceutical Sciences, Vol. 96, 1366-1379 (2007)

( 2007 Wiley-Liss, Inc. and the American Pharmacists Association the early 1996, but 2 years later most of the final product lots started to fail in the dissolution tests. It was found that during storage, the drug converted to a new, until then unknown, thermodynamically more stable but less soluble polymorph of ritonavir, leading to a loss of bioactivity. ${ }^{1-4}$ Another example of loss of activity has been reported for phenytoin (a drug used to control epilepsy), due to storage of the capsules in damp and cool conditions. ${ }^{5}$ This has generated a demand to develop fast and flexible methods of measurement of polymorphic and pseudopolymorphic transformations inline during pharmaceutical processing and storage procedures.

It has been reported that approximately onethird of pharmaceutical solids are able to form hydrate species, depending on the environmental conditions. ${ }^{6}$ This solid-state transformation can have significant effects on a variety of physical and chemical properties, and eventually modify the pharmaceutical properties, such as solubility, dissolution and bioavailability. ${ }^{7,8}$ Thus, detection and understanding of the interactions of water and 
drugs is of utmost relevance in order to improve and control the quality of the final product.

Raman spectroscopy is a structure-rich probe that provides an excellent method for probing solid-state hydrogen bonding interactions between molecules, including polymorphs and solvates (including hydrates). ${ }^{9-17}$ Despite the similar information content of Raman and infrared absorption (IR) spectroscopies, Raman presents several advantages over IR. In the particular context of the present work, the most relevant advantage is the low Raman activity of water vibrations, whose strong infrared activity tends to mask a wide IR spectrum range. Thus, Raman spectroscopy has been successfully used for monitoring the hydration and dehydration processes of different sugars, such as glucose and cyclodextrins, ${ }^{18-24}$ and pharmaceutical drugs. ${ }^{7,25-28}$

Theophylline [1,3-dimethyl-xanthine, hereafter named by TP (Fig. 1)] is a natural derivative of xanthine found mainly in tea, which presents several pharmaceutical and medical applications, ${ }^{29-31}$ and is included in the core essential medicines list of the World Health Organization (WHO). ${ }^{32}$ It has been shown that TP easily undergoes reversible anhydrous $\leftrightarrow$ hydrate transformations, which significantly affect its solubility and, consequently, its bioavailability. ${ }^{33-35}$ Thus, an evaluation of the hydration and dehydration behavior and kinetics of TP is particularly relevant in the development of stable formulations of the drug.

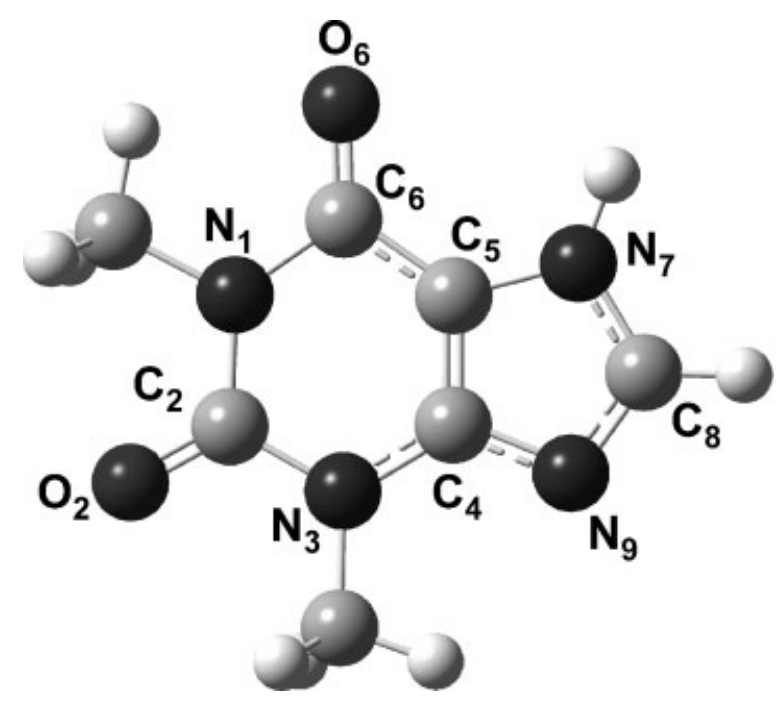

Figure 1. Schematic representation of theophylline and atom numbering used in the text.
TP has been reported to exist in a pseudopolymorphic monohydrated form (hereafter named as $\mathrm{TPh}$ ) and a pair of enantiotropic anhydrous polymorphs, named forms I and II. ${ }^{35-38}$ Anhydrous form II (hereafter named as TPa) is stable at room temperature, while form I only occurs at very high temperatures. In addition, an anhydrous metastable form, which is monotropic in respect to $\mathrm{TPa}$, has also been characterized. ${ }^{35-38}$ This metastable polymorph (hereafter named as TPm) is known to form during dehydration at low drying temperatures.

The crystal structures of both TPa and TPh have been published, ${ }^{39-41}$ being evident that the major structural differences between the two polymorphs occur in the hydrogen-bonding network. These structural differences have a direct effect on the vibrational spectra (both in the position and in the relative intensities of the bands) as was reported previously by some of us. ${ }^{42}$ Thus, neglecting the hydration effects on the vibrational spectra can be misleading in further vibrational studies on $\mathrm{TP}$, as was observed in a study by Gunasekaran et al. ${ }^{43}$ (for details see Reference $^{42}$ ).

As stated previously, theophylline easily undergoes $\mathrm{TPa} \rightarrow \mathrm{TPh}$ and $\mathrm{TPh} \rightarrow \mathrm{TPa}$ transformations, and both processes have been studied for the bulk powder $^{38,44-56}$ and for tablets. ${ }^{57-60}$ The effects of different excipients on these hydration and dehydration processes have also been evaluated by different authors. ${ }^{28,61-64}$ Unfortunately, however, these studies not only use different techniques (ranging from thermogravimetric methods to spectroscopic tools), but they also consider very different experimental conditions (temperature, humidity, sample handling and preparation), known to have a great influence on both pseudopolymorphic transformations. This fact is probably the origin of some of the discrepancies found in the literature. For instance, the results of Otsuka et al. ${ }^{57,58}$ suggest that the hydration rate of TPa tablets decreases with increase of tableting pressure and of porosity, while contradictory results were obtained by Suihko et al. ${ }^{38}$ In what concerns the dehydration process of TPh, different kinetic mechanisms have been suggested. $^{44,51-53,55,57,58}$ Moreover, very different values were also determined for the activation energy $\left(E_{\mathrm{a}}\right)$ of the process. ${ }^{44,51-53,55,57,58}$ In an attempt to explain these discrepancies, Agbada and York $^{51}$ even suggested that both process mechanism and activation energy are techniquedependent. Of course, it is more likely that the 
differences are due to the different experimental conditions used by the authors.

Attending to the factors described above, it is particularly important to study the two processes using the same experimental methodology (milling degree, temperature, humidity, and analysis technique). In this context, the methodology used for the preparation of the samples (see Experimental Section) was found to yield kinetic parameters that are not influenced by sample weight, at least in the range considered (119$60 \mathrm{mg}$ ). Moreover, the use of Raman spectroscopy has the advantage of allowing the simultaneous determination of the kinetic parameters of the process and of the structural changes underlying it.

In the present work, the hydration and the dehydration kinetics of TP are monitored by means of FT-Raman spectroscopy. In the hydration process, the commercial anhydrous form is exposed to water atmosphere during different time intervals, while for the dehydration process samples of the crystallized hydrated form are stored at different ambient temperatures during different time periods. In addition, the critical relative humidity $(\mathrm{RH})$ values for both anhydrous and hydrate forms are determined.

\section{RESULTS AND DISCUSSION}

This section is organized in two main parts. Firstly, the technique, the selection of the spectral regions and the selection of the kinetic parameters are described. Secondly, the results regarding the kinetic parameters and the critical humidity conditions for the hydration and dehydration of TP forms are presented and discussed.

In a typical Raman spectrum, the intensity of the scattered light is plotted as a function of the Raman shift $\left(\Delta v \mathrm{~cm}^{-1}\right)$. The observed intensity of a Raman band (at a particular Raman shift) is given by

$$
I_{\mathrm{A}}=\delta_{\mathrm{A}} \times C_{\mathrm{A}}
$$

where $I_{\mathrm{A}}$ is the observed intensity of the band associated to component $\mathrm{A}, \delta_{\mathrm{A}}$ is the Raman activity (intrinsic intensity) of the corresponding vibrational mode, and $C_{\mathrm{A}}$ is the relative concentration of component $A$ in the sample (in the scope of the present work, the relative concentration of a given polymorphic or pseudopolymorphic form).

In order to use Raman spectroscopy in the evaluation of kinetic parameters, it is firstly necessary to identify the distinct bands due to the different polymorphic or pseudopolymorphic forms intervening in the reaction pathway, "reactant" and "product." Among a given pair of bands ascribed to the "reactant" and "product," there will be a time-dependent intensity transfer during the reaction.

\section{Selection of the Most Useful Spectral Regions}

Figure 2 compares the Raman spectra of TPa and $\mathrm{TPh}$ pure forms (bottom and top, respectively) in

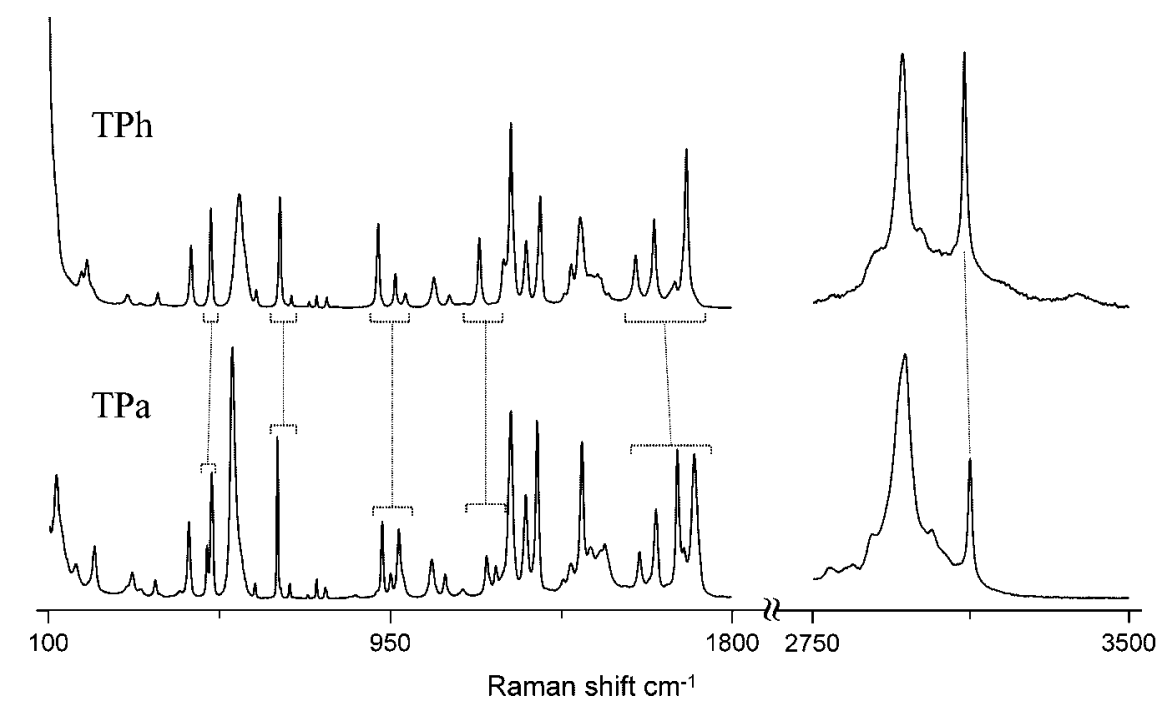

Figure 2. FT-Raman spectra of TPa (bottom) and TPh (top) in the $100-1800 \mathrm{~cm}^{-1}$ and $2750-3500 \mathrm{~cm}^{-1}$ spectral regions. The regions showing the most pronounced differences between TP forms are marked. 
the $100-1800 \mathrm{~cm}^{-1}$ and $2750-3500 \mathrm{~cm}^{-1}$ spectral regions. The horizontal brackets emphasize the spectral regions that evidence the most prominent spectral differences. As can be seen, the spectral differences between the $\mathrm{TPa}$ and $\mathrm{TPh}$ forms spread out through almost the entire spectral range. According to a previous study, ${ }^{65}$ these are related to the stretching modes of the oscillators $\mathrm{C}_{(8)}-\mathrm{H}\left(3060-3160 \mathrm{~cm}^{-1}\right), \mathrm{C}=\mathrm{O}\left(1650-1750 \mathrm{~cm}^{-1}\right)$, $\mathrm{C}_{(4)}=\mathrm{C}_{(5)}\left(1585-1630 \mathrm{~cm}^{-1}\right)$ and $\mathrm{C}-\mathrm{C}$ and $\mathrm{C}-\mathrm{N}$ (1540-1585 $\mathrm{cm}^{-1}, 1300-1340 \mathrm{~cm}^{-1}$, and $1160-$ $1203 \mathrm{~cm}^{-1}$ ). The remaining regions shown are mainly ascribed to deformation modes of the imidazole and pyrimidine rings.

All these spectral regions were evaluated for their suitability to be used in the relative quantification of the two forms, $\mathrm{TPa}$ and $\mathrm{TPh}$, using physical mixtures of known $\mathrm{TPa} / \mathrm{TPh}$ ratio. Two main criteria were considered. Firstly, the existence of an isosbestic point is required. It is generally accepted that the existence of an isosbestic point is an indication that only two species exist in the pathway of a reaction, and that they interconvert directly. ${ }^{66}$ Secondly, the number of bands required for the spectral deconvolution process should be low, as the spectral regions that can be described using two single bands in the deconvolution process are less prone to "overparameterization" errors.

Figure 3 shows the Raman spectra of TPa and $\mathrm{TPh}$ in the $3060-3160 \mathrm{~cm}^{-1}, 900-940 \mathrm{~cm}^{-1}$, and $650-685 \mathrm{~cm}^{-1}$ spectral regions. These regions were found to be the most amenable for the present study, as they present a clear isosbestic point and can be described by the presence of two single bands. Being so, these are the only regions used in the scope of the present work (hydration of $\mathrm{TPa}$ and dehydration of $\mathrm{TPh}$ ). However, in studies involving mixtures of compounds, such as mixtures of TP and excipients, the use of other spectral regions may be required, as it naturally depends on the degree of overlapping between the TP and excipient bands (see Experimental Section for more details).

\section{Determination of Kinetic Parameters}

Different kinetic models $(f(\alpha)=\mathrm{kt}$, where $\alpha$ stands for the fractional of conversion) have been defined for characterizing the solid-solid reaction mechanisms, such as the present pseudopolymorphic conversions (Tab. 1) ${ }^{67-69}$ By plotting $f(\alpha)$ versus time-of-reaction, a linear relation shall be obtained, with the corresponding slope giving the reaction rate of the process.

The values of the fractional of conversion can be determined by using the relative intensity ratio of the Raman bands ascribed to each form, TPa and $\mathrm{TPh}$. That is, the values of the fractional of hydration $\left(\alpha_{h}\right)$ and of dehydration $\left(\alpha_{d}\right)$ at a particular time-of-reaction (of time-of-exposure to $\mathrm{RH}$ conditions or of time-of-storage at a given temperature) can be determined as

$$
\alpha_{\mathrm{h}}(t)=\frac{I_{\mathrm{TPh}}}{\left[\boldsymbol{I}_{\mathrm{TPh}}+\left(\delta_{\mathrm{TPh}} / \delta_{\mathrm{TPa}}\right) I_{\mathrm{TPa}}\right]}
$$

and

$$
\alpha_{\mathrm{a}}(t)=\frac{I_{\mathrm{TPa}}}{\left[\boldsymbol{I}_{\mathrm{TPa}}+\left(\delta_{\mathrm{TPa}} / \delta_{\mathrm{TPh}}\right) I_{\mathrm{TPh}}\right]}
$$

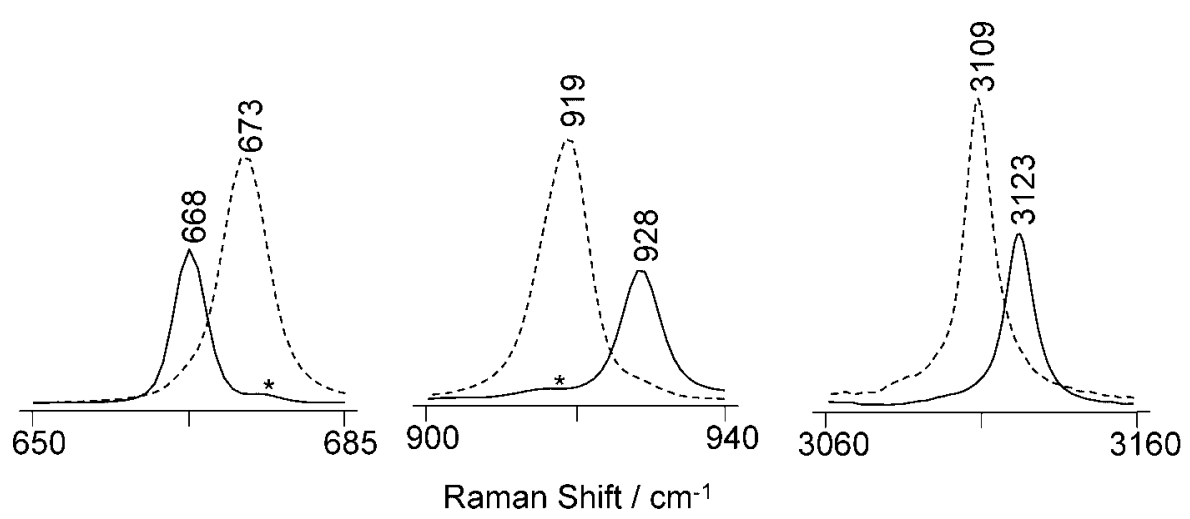

Figure 3. Comparison of the FT-Raman spectra of TPa (solid line) and TPh (dashed line) forms in the $650-685 \mathrm{~cm}^{-1}, 900-940 \mathrm{~cm}^{-1}$, and $3060-3160 \mathrm{~cm}^{-1}$ spectral regions. The band intensities are scaled in accordance to the intrinsic intensities of the corresponding vibrational modes. The spectral features marked with an asterisk are ascribed to the metastable TPm form (see text). 
Table 1. Solid-State Reaction Rate Equations and Mechanisms ${ }^{67-69}$

\begin{tabular}{lll}
\hline Model & Equation, $f(\alpha)=\mathrm{kt}^{a}$ & Rate-Controlling Mechanism \\
\hline M1 & $\alpha^{1 / 4}$ & Power law \\
M2 & $\alpha^{1 / 3}$ & Power law \\
M3 & $\alpha^{1 / 2}$ & Power law \\
M4 & $\alpha^{3 / 2}$ & Power law \\
M5 & $1-\alpha$ & One-dimensional phase boundary reaction (zero-order) \\
M6 & $1-(1-\alpha)^{1 / 2}$ & Two-dimensional phase boundary reaction (cylindrical symmetry) \\
M7 & $1-(1-\alpha)^{1 / 3}$ & Three-dimensional phase boundary reaction (spherical symmetry) \\
M8 & $-\ln (1-\alpha)$ & Random nucleation (Mampel equation) \\
M9 & $(-\ln (1-\alpha))^{1 / 2}$ & Random nucleation (Avrami-Erofeev equation; $n=1 / 2)$ \\
M10 & $(-\ln (1-\alpha))^{1 / 3}$ & Random nucleation (Avrami-Erofeev equation; $n=1 / 3)$ \\
M11 & $(-\ln (1-\alpha))^{1 / 4}$ & Random nucleation (Avrami-Erofeev equation; $n=1 / 4)$ \\
M12 & $(-\ln (1-\alpha))^{2 / 3}$ & Random nucleation (Avrami-Erofeev equation; $n=2 / 3)$ \\
M13 & $\alpha$ & Zero-order mechanism (Polany-Wigner equation) \\
M14 & $\alpha^{2}$ & One-dimensional diffusion \\
M15 & $(1-\alpha) \ln (1-\alpha)+\alpha$ & Two-dimensional diffusion \\
M16 & $\left(1-(1-\alpha)^{1 / 3}\right)^{2}$ & Three-dimensional diffusion (Jander equation) \\
M17 & $1-\frac{2}{3} \alpha-(1-\alpha)^{2 / 3}$ & Three-dimensional diffusion (Ginstling-Brounshtein equation) \\
\hline
\end{tabular}

${ }^{a} \alpha$ stands for $\mathrm{TPa} \rightarrow \mathrm{TPh}$ or $\mathrm{TPh} \rightarrow \mathrm{TPa}$ degree of conversion; $k$ is the rate constant of the conversion reaction; $t$ is time-of-exposure to water atmosphere.

respectively ( $I$ stands for intensity of the bands ascribed to the TPh and TPa forms at instant $t$ of reaction, respectively, and $\delta$ stand for the intrinsic intensity of the vibrational mode considered). By definition, $\alpha_{\mathrm{h}}+\alpha_{\mathrm{a}}=1$.

The different kinetic models of Table 1 were considered in order to identify the mechanism underlying either the $\mathrm{TPa} \rightarrow \mathrm{TPh}$ and the $\mathrm{TPh} \rightarrow$ TPa conversions.

\section{Hydration Process of TPa}

Figure 4 shows the sequential change of the $\mathrm{C}_{8}-\mathrm{H}$ stretching mode spectral region (3060$3160 \mathrm{~cm}^{-1}$ ) as a function of time-of-exposure to water saturated atmosphere, at $25^{\circ} \mathrm{C}$. The timedependent intensities observed in the 900$940 \mathrm{~cm}^{-1}$ and $650-685 \mathrm{~cm}^{-1}$ spectral regions present a similar behavior (Fig. $5 \mathrm{~S}$ of the Supplementary Material).

The first evidences of the pseudopolymorphic transformation are detectable after more than $1 \mathrm{~h}$ of exposure. On the other hand, after $6 \mathrm{~h}$ of exposure the band ascribed to the TPa form is just a weak shoulder, which disappears after $8 \mathrm{~h}$ of exposure. Larger times of exposure did not give rise to any further eye-observable spectral change, although a good band fitting evidenced the presence of small amounts of the TPa form (ca. 1\%) until up to $c a .10 \mathrm{~h}$ of exposure.

Figure 5 collects the plots of $\alpha_{\mathrm{h}}$ (Eq. 2) as a function of time, for the three spectral regions. The values obtained from moisture uptake gravimetric measurements are also shown for comparison. As can be seen, all the results are in very good agreement. Both the fractional of total moisture uptake $\left(x_{\mathrm{TPh}}\right)$ and fractional of hydration $\left(\alpha_{\mathrm{h}}\right)$ follow very similar sigmoidal curves as a function of time-of-exposure to water saturated atmosphere (Fig. 5a).

Both quantities $x_{\mathrm{TPh}}$ and $\alpha_{\mathrm{h}}$ were fitted to the different kinetic models listed in Table 1 , and it was found that in all cases the hydration of TPa is better described by the Avrami-Erofeev random nucleation approach (Fig. 5b and Tab. $2 \mathrm{~S}$ of the Supplementary Material). Table 2 shows the kinetic results obtained for the TPa hydration process, using moisture uptake and Raman measurements. Although the obtained $R^{2}$ - and $s_{\mathrm{b}}$-values for M9 and M10 kinetic models are somewhat similar, the former was assumed to yield a better description of the overall results (three spectroscopic regions and moisture uptake measurements). Within this assumption, the hydration of TPa is a one-step random nucleation process, described by the Avrami-Erofeev equation of exponent $\frac{1}{2}$, with a rate constant of ca. $0.003 \mathrm{~min}^{-1}$. The gravimetric moisture uptake results point to a $t_{1 / 2}$ of $c a .276 \mathrm{~min}$. On the other hand, according to the Raman experiments half-hydration is obtained after 292-299 min. In addition, while the gravimetric results indicate completeness of TPa hydration after ca. 1064 min. of exposure, the FT-Raman 


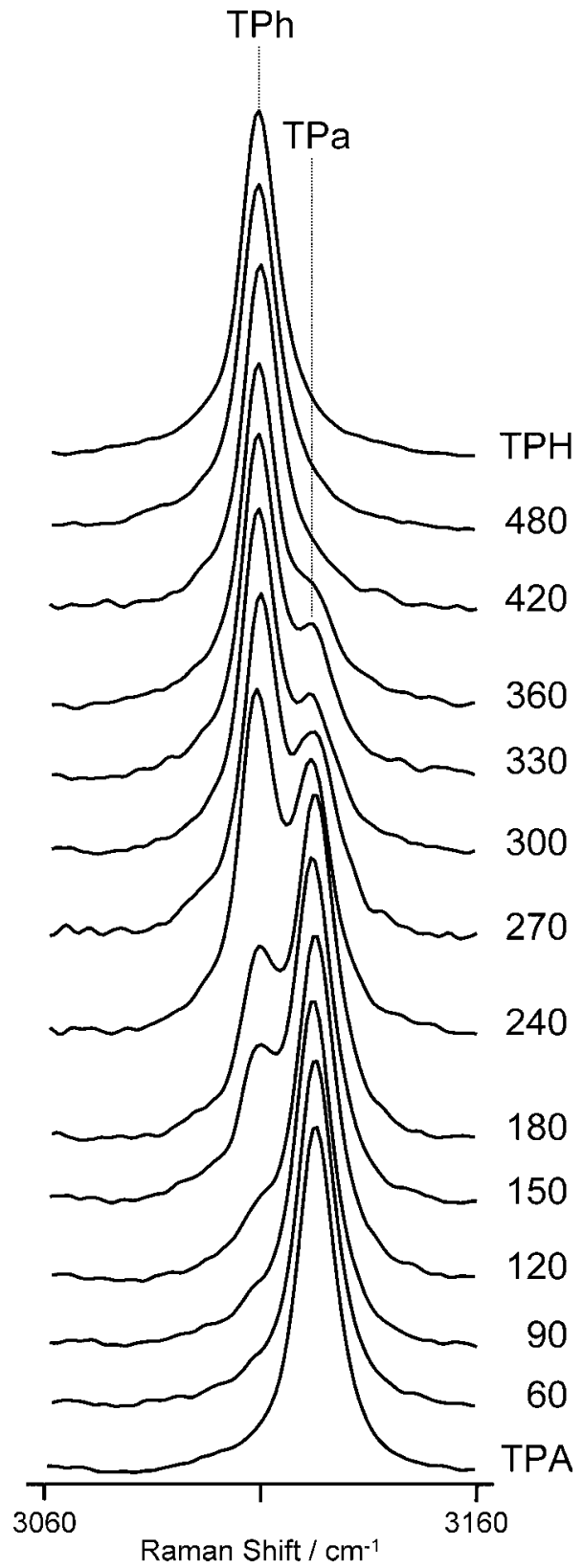

Figure 4. FT-Raman spectra, in the $3060-3160 \mathrm{~cm}^{-1}$ region, of TP as a function of time of exposure to $\mathrm{RH}=100 \%$. The time of exposure (in minutes) is shown in the right-hand side. Equivalent plots for 650$685 \mathrm{~cm}^{-1}$ and $900-940 \mathrm{~cm}^{-1}$ spectral regions are presented in Figure 4S of the Supplementary Material.

measurements yield values in the range of 1088$1180 \mathrm{~min}$.

As can be seen in the last lines of Table 2, different kinetic parameters for the TPa hydration process (namely times required for half-hydration $\left(t_{1 / 2}\right)$ and complete hydration $\left.\left(t_{\mathrm{h}}\right)\right)$ have been reported in the literature. ${ }^{44,45,49}$ The results
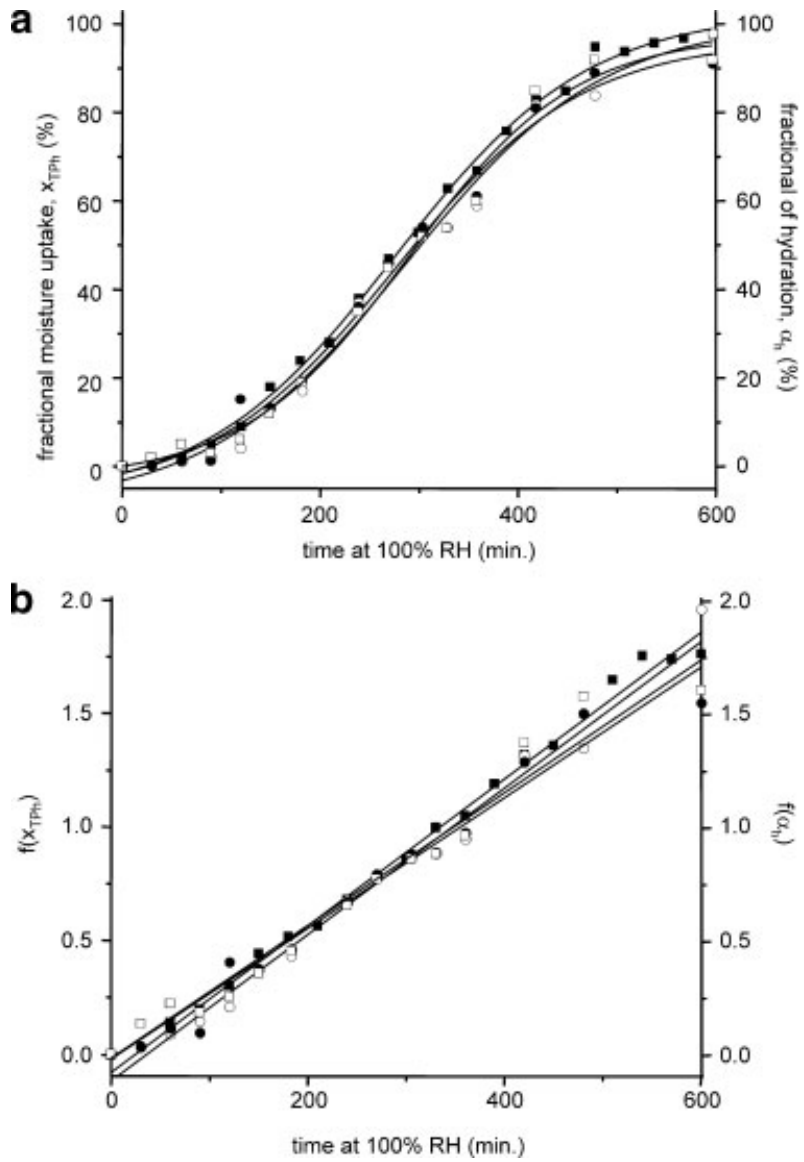

Figure 5. Kinetic data for the TPa hydration process obtained by moisture uptake measurements (black squares) and spectral band deconvolution of the 3060$3160 \mathrm{~cm}^{-1}$ (white circles), 650-685 $\mathrm{cm}^{-1}$ (black circles), and $900-940 \mathrm{~cm}^{-1}$ (white squares) spectral regions: (a) plot of fractional moisture uptake $\left(x_{\mathrm{TPh}}\right)$ and $\alpha_{\mathrm{h}}$ (Eq. 2) as a function of time-of exposure to $\mathrm{RH}=100 \%$. (b) Fitting of $x_{\mathrm{TPh}}$ - and $\alpha_{\mathrm{h}}$-values to the Avrami-Erofeev random nucleation $(n=0.5)$ equation.

obtained in the present work differ significantly from all the previously reported values. These discrepancies can have several explanations. The most evident is associated with the different history of the TPa samples used. For instance, in the present work the commercial TPa samples were used, while in the remaining works the TPa samples were obtained by dehydration of TPh, which can lead to significantly different sample morphologies (e.g., grain size and crystal defects). In fact, it has been found that particle dimensions affect significantly the hydration rate of $\mathrm{TPa},{ }^{51,58}$ while Ono et al ${ }^{56}$ reported that the increase of dehydration temperature decreases the rate of moisture uptake. 
Table 2. Values of Rate Constant of Hydration $(k)$, Standard Deviation of the Slope $\left(s_{\mathrm{b}}\right)$, Correlation Coefficient $\left(R^{2}\right)$ and Times of Half-Hydration $\left(t_{1 / 2}\right)$ and Complete Hydration $\left(t_{\mathrm{h}}\right)$, Obtained for the Best Linear Fits $(f(\alpha))$ Obtained for the Three Spectral Regions Considered and for the Moisture Measurements

\begin{tabular}{lrrrrrrr}
\hline Spectral Region $\left(\mathrm{cm}^{-1}\right)$ & Model & $f(\alpha)$ & $\begin{array}{c}k \\
\left(\mathrm{~min}^{-1}\right)\end{array}$ & $s_{\mathrm{b}}$ & $R^{2}$ & $t_{1 / 2}{ }^{a}(\mathrm{~min})$ & $t_{\mathrm{h}}{ }^{b}(\min )$ \\
\hline $3060-3160$ & M9 & $-0.11034+0.00322 \mathrm{t}$ & 0.00322 & 0.00012 & 0.9847 & 292 & 1087 \\
& M10 & $0.07016+0.00258 \mathrm{t}$ & 0.00258 & 0.00009 & 0.9851 & 314 & 849 \\
$900-940$ & M9 & $-0.02822+0.00294 \mathrm{t}$ & 0.00294 & 0.00016 & 0.9697 & 292 & 1163 \\
& M10 & $0.15604+0.00233 \mathrm{t}$ & 0.00233 & 0.00014 & 0.9624 & 311 & 903 \\
$650-685$ & M9 & $-0.04071+0.00291 \mathrm{t}$ & 0.00291 & 0.00014 & 0.9754 & 299 & 1179 \\
Moisture uptake & M9 & $-0.08399+0.00329 \mathrm{t}$ & 0.00329 & 0.00010 & 0.9856 & 278 & 1056 \\
& M10 & $0.20171+0.00231 \mathrm{t}$ & 0.00231 & 0.00008 & 0.9815 & 294 & 891 \\
From Reference & & & & & & $\approx 580$ & $\approx 890$ \\
From Reference $^{45 d}$ & & & & & & $\approx 1320$ & $\approx 2700$ \\
& & & & & & $\approx 840$ & $\approx 1980$ \\
From Reference $^{44 e}$ & & & & & $\approx 1047$ & $\approx 2880$ \\
\hline
\end{tabular}

\footnotetext{
${ }^{a}$ Time for half-hydration $(f(\alpha)$ is equal to 0.83 and 0.88 for M9 and M10, respectively, using $\alpha=0.5)$.

${ }^{b}$ Time for total hydration $(f(\alpha)$ equal to 3.39 and 2.26 for M9 and M10, respectively, using $\alpha=0.99999$ ).

${ }^{c}$ Inferred from Figure 1 of Reference ${ }^{49}$; dynamic vapor sorption using $95 \% \mathrm{RH}$ after dehydration of $\mathrm{TPh}$ at $25^{\circ} \mathrm{C}$.

${ }^{d}$ Inferred from Figure 3 of Reference ${ }^{45}$; gravimetry and microcalorimetry after dehydration of $\mathrm{TPh}$ at $110^{\circ} \mathrm{C}$.

${ }^{e}$ Inferred from Figure 5 of Reference ${ }^{44}$; moisture uptake using $95 \% \mathrm{RH}$ after dehydration of $\mathrm{TPh}$ at $95^{\circ} \mathrm{C}$.

The results obtained for the linear fitting of the $x_{\mathrm{TPh}}$ values as a function of time-of-exposure to water atmosphere, obtained by sample weighting, are included in the last line. Experimental values of $t_{1 / 2}$ and $t_{\mathrm{h}}$ inferred from the literature are included.
}

The two kinetic quantities $t_{1 / 2}$ and $t_{\mathrm{h}}$ (Tab. 2) indicate the existence of a small time lag, of ca. 15-20 min, between the moisture uptake and the observation of spectral changes due to hydration. This time lag is easily explained by the two phenomena involved in the hydration process of TPa: firstly, the water molecules adsorb to the surface of the sample, then they diffuse between TP molecules, leading to the formation of water channels (thus, initiating the real $\mathrm{TPa} \rightarrow \mathrm{TPh}$ conversion). The gravimetric measurements do not distinguish between "structural" and "surface adsorbed" water molecules, while the selected regions of the Raman spectra are only sensitive to the structural changes underlying the $\mathrm{TPa} \rightarrow \mathrm{TPh}$ transformation.

\section{Critical RH for TPa Hydration}

Pharmaceutical processing may involve contact with water in different stages of final product preparation. On the other hand, drug substances and final drug products are currently submitted to different temperature and $\mathrm{RH}$ conditions due, for instance, to various climatic conditions. This can give rise to unexpected hydration aging phenomena that affect the dissolution profiles. ${ }^{31,61}$ Thus, knowledge of the critical $\mathrm{RH}$ of a particular drug is essential to obtain a stable final dosage. In the case of $\mathrm{TPa}$, the value of the critical $\mathrm{RH}$ is controversial and values ranging from $25 \%$ to $82 \%$ (for temperatures around $25^{\circ} \mathrm{C}$ ) have been reported. ${ }^{44,47,70}$

Figure $6 \mathrm{a}$ shows the Raman spectra, in the region of $3060-3160 \mathrm{~cm}^{-1}$, obtained for samples of $\mathrm{TPa}$ (commercial powder) stored at different $\mathrm{RH}$ values for 1 week at $22^{\circ} \mathrm{C}$, and illustrates the general behavior observed in all the studied regions. The corresponding plot of $\alpha_{h}$ ratio versus $\mathrm{RH}$ is shown in Figure 6b. Spectral evidences of the presence of the $\mathrm{TPh}$ form only occur for $\mathrm{RH}>79 \%$, while evidences of the presence of the TPa form completely vanish for $\mathrm{RH}>86 \%$. The $\alpha_{h}$ ratio is 0.23 and 0.86 for the samples exposed to $\mathrm{RH}=81 \%$ and $\mathrm{RH}=84 \%$, respectively.

These results indicate that $\mathrm{TPa}$ exhibits low hygroscopicity over a wide range of $\mathrm{RH}$ conditions and the $\mathrm{TPa} \rightarrow \mathrm{TPh}$ conversion occurs in a narrow range of $\mathrm{RH}$ values. The critical $\mathrm{RH}$ value for the $\mathrm{TPa} \rightarrow \mathrm{TPh}$ conversion obtained from this study $(\mathrm{RH}>79 \%)$ is similar to that obtained by Otsuka et al. $^{44}$ in a systematic temporal study of the pseudomorphic transformation of $\mathrm{TPa}$ powder exposed to different $\mathrm{RH}$ conditions up to 10 days, by means of sample weighing.

\section{Dehydration Process of TPh}

Figure 7 presents the isothermal moisture desorption curves obtained for $\mathrm{TPh}$ from gravimetric 

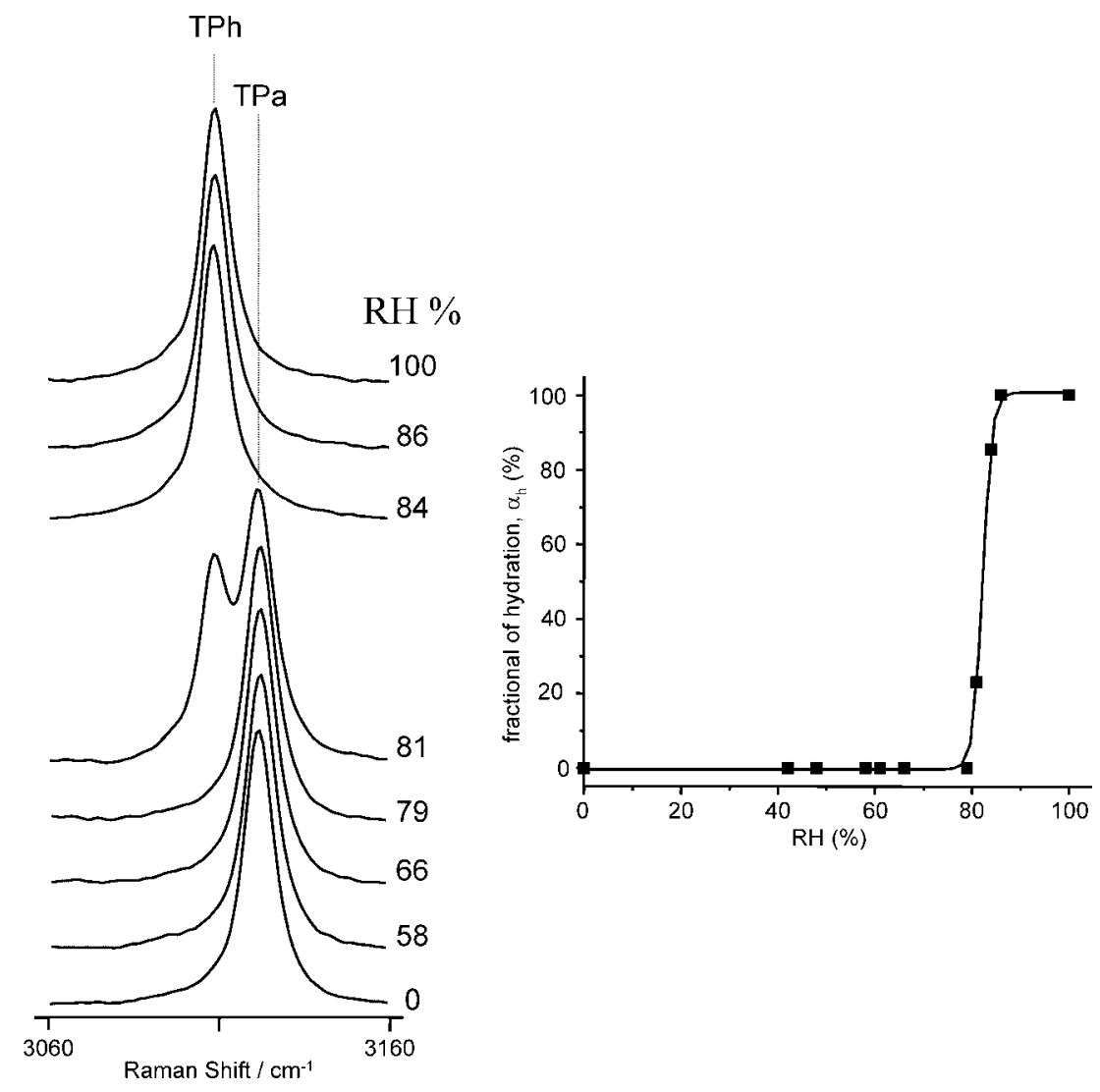

Figure 6. Partial Raman spectra, in the region of $3060-3160 \mathrm{~cm}^{-1}$, obtained for samples of $\mathrm{TPa}$ (commercial powder) stored at different $\mathrm{RH}$ values for 1 week at $22^{\circ} \mathrm{C}$ (left side) and plot of the measured $\alpha_{\mathrm{h}}$ ratio as a function of the $\mathrm{RH}$-values. Equivalent plots for the $650-685 \mathrm{~cm}^{-1}$ and $900-940 \mathrm{~cm}^{-1}$ spectral regions are presented in Figure $6 \mathrm{~S}$ of the Supplementary Material.

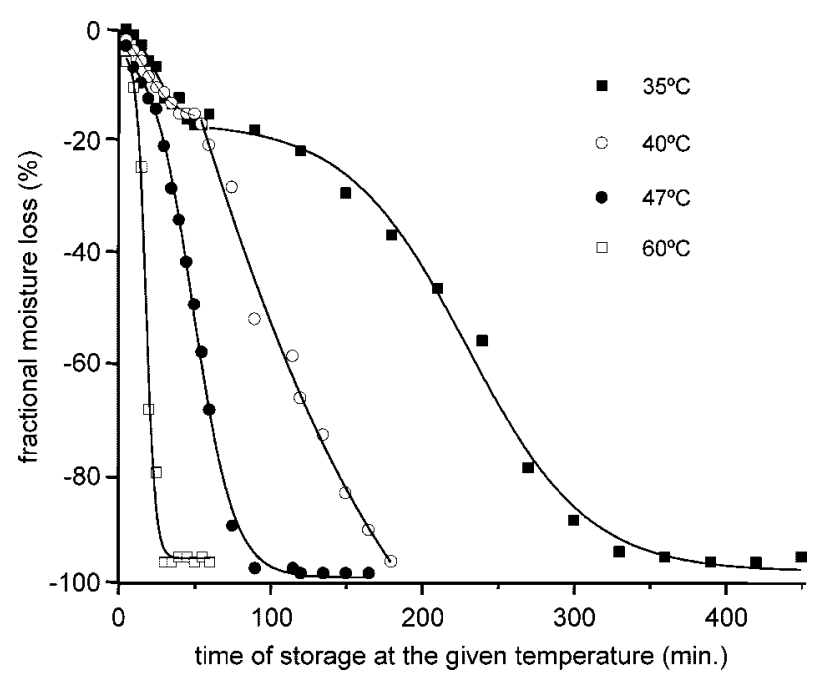

Figure 7. Isothermal moisture desorption curves obtained for TPh from gravimetric measurements at four different temperatures: $35,40,47$, and $60^{\circ} \mathrm{C}$ as a function of time. measurements at four different temperatures: 35 , 40,47 , and $60^{\circ} \mathrm{C}$.

At $60^{\circ} \mathrm{C}$, the dehydration of $\mathrm{TPh}$ is complete after about $30 \mathrm{~min}$, in agreement with the results reported in previous studies. ${ }^{36,51}$ As expected, the time required to complete dehydration increases as temperature decreases, being of the order of $\mathrm{ca}$. 120,200 , and $400 \mathrm{~min}$ at 47,40 , and $35^{\circ} \mathrm{C}$, respectively.

All the curves present a "double-sigmoid" profile, with a region of slower mass decrease (plateau) at ca. $17 \%$ water loss. This region becomes quite evident for the $35^{\circ} \mathrm{C}$ results, but can be also detected in the plots of the remaining temperature studies. The existence of regions with different dehydration-rates is a strong evidence of a multi-step dehydration process. Although the studies of Shefter et al. ${ }^{53}$ and Agbada and York ${ }^{51}$ seem to indicate that dehydration of TPh occur in a one-step process, several other studies suggest that the process may present two steps, depending on 
the experimental conditions (namely, dehydration temperature). ${ }^{36,37,52,54,55}$

In fact, the definition of the experimental conditions is critical in these studies. For instance, Duddu et al. ${ }^{52}$ concluded that TPh dehydration is a single-step process at $47^{\circ} \mathrm{C}$ the, while at $40^{\circ} \mathrm{C}$ it involves two distinct steps. However, they used a period of sample equilibration of $25 \mathrm{~min}$, whichaccording to our results-includes the first step for the $47^{\circ} \mathrm{C}$ conditions.

Evidences of the two-step process in TPh dehydration are also observed in the Raman spectra, as the observed spectral changes follow the two periods of the isothermal moisture desorption curves shown in Figure 7. In fact, for each temperature studied, the first evidences of the presence of the TPa form only appear after a time period corresponding to the end of the plateau observed in the corresponding isothermal moisture desorption curve. This means that the $\mathrm{TPh} \rightarrow \mathrm{TPa}$ transformation is delayed relative to the starting of the dehydration process by $c a, 120$, 80,20 , and $15 \mathrm{~min}$ of storage at $35,40,47$, and $60^{\circ} \mathrm{C}$, respectively.

During this time interval, no changes are observed in the Raman spectra of the samples, despite the loss of $c a .17 \%$ of their water content. The only exception occurs in the $1215-1270 \mathrm{~cm}^{-1}$ region, where a slight intensity increase of a band centered at $c a .1231 \mathrm{~cm}^{-1}$ is observed during the first time period (until end of the plateau), while its disappearance is be expected on passing from $\mathrm{TPh}$ to $\mathrm{TPa}$ (in fact, it is absent in the spectrum of $\mathrm{TPa}$ ). Based on this information, the band was assigned to the metastable form TPm. ${ }^{65}$

On the whole, the two experiments (weighting and FT-Raman measurements) are consistent with a two-step mechanism for the pseudomorphic $\mathrm{TPh} \rightarrow \mathrm{TPa}$ transformation (the vibrational modes in both TPh and TPm forms occur at very similar wavenumbers). The second step starts when the low water content triggers the collapse of the TPm form to the TPa structure. After this point, which is dependent on the storage temperature, the dehydration evolves further at constant rate, as indicated by the mass decrease in the gravimetric studies and by the increase of the Raman bands assigned to the TPa form.

The formation of a metastable form during the dehydration of $\mathrm{TPh}$ at defined temperatures has been widely referred in the literature. ${ }^{35-37}$ According to Phadnis et al. ${ }^{35}$ and Karjalainen et al., ${ }^{37}$ this form only appears if the dehydration is performed at temperatures above $40^{\circ} \mathrm{C}$. However, the herein presented results clearly indicate that this species can form at all storage temperatures. Even at temperature of $22^{\circ} \mathrm{C}$, with appropriate $\mathrm{RH}$ conditions to induce the dehydration, the FT-Raman spectra evidence the formation of the metastable form. Its conversion to the TPa polymorph (the room-temperature stable species) is as faster as higher the storage temperature, thus turning its detection more or less feasible.

The involvement of this metastable form in the conversion pathway precludes the evaluation of the kinetics of the dehydration process. This is probably the reason why the reported kinetic results of the literature (values of rate constants and choice of the kinetic model) are so different from each other. ${ }^{44,45,49}$ However, it is possible to evaluate the kinetic parameters for the second step, using the points shown in Figure 7 after the plateau. The results for this second step can be identically described by either the AvramiErofeev models or by the simple a zero-order diffusion mechanism $\left(r^{2}\right.$ values and $s_{\mathrm{b}}$ values within $0.98-0.99$ and $0.00030-0.00060$ intervals, respectively).

$$
\begin{array}{ll}
\mathrm{TPh}(\text { solid }) \rightarrow \mathrm{TPm}(\text { solid })+\mathrm{H}_{2} \mathrm{O}(\text { gas }) & \begin{array}{l}
\text { dehydration step } \\
\text { structural conversion step }
\end{array} \\
\mathrm{TPm}(\text { solid }) \rightarrow \mathrm{TPa}(\text { solid }) &
\end{array}
$$

In the first step, the sample starts to lose water until approximately $17 \%$ of the total water has been lost. This gives rise to a metastable form, which corresponds to a polymorphic species of transition (TPm) that retains the $\mathrm{TPh} \cdots \mathrm{TPh}$ intermolecular interactions of the hydrate. The metastable form retains the hydrate main structural characteristics, which explains why there are nearly no Raman spectral evidences of the $\mathrm{TPh} \rightarrow \mathrm{TPm}$ transformation during this step

\section{Critical RH for TPh}

To best of our knowledge, the critical RH condition for the $\mathrm{TPh} \rightarrow \mathrm{TPa}$ conversion have not been evaluated. Zhu et al. ${ }^{70}$ report a value of 0.25 for the critical water activity for TP solutions in organic solvent + water mixtures. However, this value gives no clues concerning the behavior of samples exposed to atmosphere $\mathrm{RH}$ conditions, since it refers to direct contact with the solvent in 
saturated solutions. According to our results, the full dehydration after 1-week exposure is observed for $\mathrm{RH}=20 \%$. However, after exposure to $\mathrm{RH}=30 \%$ (at $25^{\circ} \mathrm{C}$ ), the spectrum of $\mathrm{TPh}$ already shows the presence of small amounts of $\mathrm{TPa}$. In this way, the critical RH for TP dehydration lies closely above $30 \%$.

\section{CONCLUSIONS}

Raman spectroscopy was found to be a suitable technique for the quantification of anhydrate and hydrate forms in molecular powder systems, since the vibrational spectra is highly sensitive to the strong intermolecular interactions present in these systems. In the case of theophylline, there are several spectral regions which could be used for a reliable quantification of the hydrateanhydrate phase transformations.

The hydration of $\mathrm{TPa}$ is a one-step random nucleation process, described by the AvramiErofeev equation of exponent $\frac{1}{2}$, with a rate constant of ca. $0.003 \mathrm{~min}^{-1}$, which corresponds to a half-life time of $c a .5 \mathrm{~h}$. On the other hand, the dehydration occurs through a two-step mechanism, involving a metastable form.

These observations reinforce the need for controlled storage conditions in order to avoid unwanted drug transformations. The $\mathrm{TPa} \rightarrow \mathrm{TPh}$ pseudo-morphic transformation is a temperaturecontrolled process at constant $100 \% \mathrm{RH}$ conditions, and does not require direct contact between drug and bulk water. Both pseudopolymorphic of teophylline forms are stable within the 30-79\% $\mathrm{RH}$ interval, but the conversion will occur within a day-scale for storage outside this $\mathrm{RH}$ interval.

\section{EXPERIMENTAL SECTION}

\section{TP Samples}

Anhydrous TP (TPa) was obtained commercially (Sigma-Aldrich, St. Louis, MO) and used without further purification (grain size between 250 and $125 \mu \mathrm{m})$.

TP monohydrate (TPh) was prepared by dissolving $\mathrm{TPa}$ in distilled water at $60^{\circ} \mathrm{C}$ until a supersaturated solution is prepared. When the solution was allowed to slowly cool to room temperature, needle-like crystals of the monohydrate were formed. These were filtered from the mother liquid, allowed to dry at ambient temperature and $\mathrm{RH}$ conditions, and then gently milled to fine powder (grain size between 250 and $125 \mu \mathrm{m}$ ).

\section{Sample Treatment}

In a first type of experiments, TPa samples of $c a .0 .1 \mathrm{~g}$ were transferred to small reservoirs and exposed to the water atmosphere $(\mathrm{RH}=100 \%)$, without direct contact between the sample and the bulk liquid (see Fig. 8). After defined time intervals of exposure, small amounts were quickly sealed in glass capillary tubes and the FT-Raman spectra recorded.

In a second type of experiments, TPh samples (ca. $0.1 \mathrm{~g}$ ) were submitted to different temperatures $\left(35,40,47\right.$, and $\left.60^{\circ} \mathrm{C}\right)$ during defined time periods, and sealed in glass capillary tubes in order to record their FT-Raman spectra.

Finally, the TPa and TPh samples (ca. $0.1 \mathrm{~g}$ ) were exposed to defined $\mathrm{RH}$ conditions, using the same experimental apparatus (Fig. 8), created by using saturated salt solutions with deposit. The RH-values considered (and salt used) were taken from $^{71}$ and are: $9 \%(\mathrm{KOH}), 13 \%(\mathrm{LiCl})$, $20 \% \quad\left(\mathrm{KC}_{2} \mathrm{H}_{3} \mathrm{O}_{2}\right), 30 \%\left(\mathrm{CaCl}_{2}\right) \quad 42 \% \quad\left(\mathrm{Zn}\left(\mathrm{NO}_{3}\right)_{2}\right.$, $48 \%$ (KCNS), $52 \% \mathrm{NaHSO}_{4}$ ), $58 \%(\mathrm{NaBr}), 61 \%$ $\left(\mathrm{NH}_{4} \mathrm{NO}_{3}\right), \quad 66 \% \quad\left(\mathrm{NaNO}_{2}\right), \quad 78 \% \quad\left(\mathrm{Na}_{2} \mathrm{SO}_{3}\right)$, $79 \%\left(\mathrm{NH}_{4} \mathrm{Cl}\right), 81 \%\left(\left(\mathrm{NH}_{4}\right)_{2} \mathrm{SO}_{4}\right), 84 \%(\mathrm{KBr}), 86 \%$ $\left(\mathrm{KHSO}_{4}\right)$, and $92 \%\left(\mathrm{KNO}_{3}\right)$. The $\mathrm{RHs}$ of $0 \%$ and $100 \%$ were achieved by considering anhydrous $\mathrm{CuSO}_{4}$ or silica and pure water, respectively. In all cases, the exposure time was of 1 week in order to guarantee the equilibrium moisture condition.

All experiments were performed at $22^{\circ} \mathrm{C}$ ambient temperature and repeated three times. The moisture content was evaluated in all cases by performing a parallel set of experiments, and weighing the samples before and after exposure to the desired experimental condition.

\section{FT-Raman Spectra}

The FT-Raman spectra were recorded on a RFS100 Bruker FT-spectrometer, using a Nd:YAG laser with excitation wavelength of $1064 \mathrm{~nm}$, with

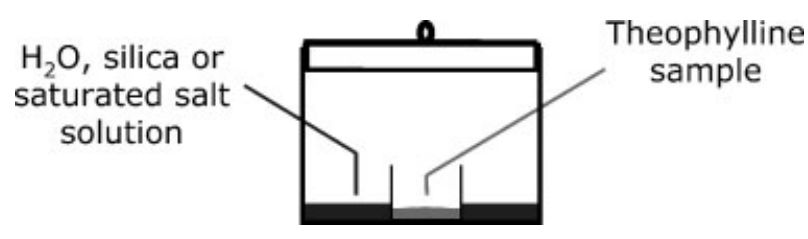

Figure 8. Schematic representation of the reservoir used for sample exposure to specific RH-values (see text) 
laser power set to $300 \mathrm{~mW}$. Each spectrum is the averaging of two repeated measurements of 100 scans each and $2 \mathrm{~cm}^{-1}$ resolution.

It has been reported that in some experiments the sample temperature can rise significantly due to laser exposure. ${ }^{72,73}$ This heating effect can, for instance, lead either to polymorphic transformations or loss of solvent molecules. In order to evaluate this effect on the present results, a sample of theophylline monohydrate was exposed continuously to $300 \mathrm{~mW}$ laser power for $2 \mathrm{~h}$. During this time, several records of 2 min each were recorded. The comparison of the spectra allowed to conclude that during the time needed for the record of each spectrum (record of two measurements of 100 scans each takes about $20 \mathrm{~min}$ ) no spectral alteration was notable. In fact, a first spectral change assignable to sample heating (denoting some loss of water molecules), although still extremely subtle, became observable after 40 min of exposure to the laser (undisputable spectral changes are only observable after about $50 \mathrm{~min}$ of exposure).

\section{Spectral Band Deconvolution and Mathematical Data Treatment}

Band areas were determined by fitting to the spectral regions used Lourentzian or Gaussian functions, after performing a linear baseline correction employing three points. The $\delta_{\mathrm{TPh}} / \delta_{\mathrm{TPa}}$ ratio, required to obtain the values of the fractional of transformation, $\alpha_{\mathrm{TPa}}$ and $\alpha_{\mathrm{TPh}}$ from the measured band intensities (see Eqs. 2 and 3), were determined by fitting procedures, using physical mixtures of both components with defined composition ( $\mathrm{TPh}$ molar fractions of 0.00 ,
$0.08,0.19,0.33,0.44,0.49,0.51,0.64,0.84,0.89$, 1.00 were used).

Different standard statistical criteria may be used to determine the aggregate deviation of a set of measured points from the calculated linear relationship. The most usually used are the correlation coefficient $\left(R^{2}\right)$ and the standard error of the slope of the regression line $\left(s_{\mathrm{b}}\right)$. Some authors ${ }^{67,74}$ have reported the inadequacies of using $r$-value as the sole determinant of the applicability of a particular kinetic model, particularly for distinguishing between mechanism that yield similar linear correlation coefficients $\left(R^{2}\right)$. Davis and Pryor ${ }^{74}$ pointed out the advantages of using $s_{\mathrm{b}}$-values instead. In this work, the quality of the linear fit obtained for each kinetic model tested (Tab. 1) is determined by considering both $R^{2}$ - and $s_{\mathrm{b}}$-values.

Table 3 presents the results obtained for the linear fitting of the predicted relative concentration as a function of the known molar fraction of $\mathrm{TPh}-\mathrm{TPa}$ physical mixtures. As stated in the Results and Discussion Section, only three spectral regions, namely $3060-3160 \mathrm{~cm}^{-1}, 900-$ $940 \mathrm{~cm}^{-1}$, and $650-685 \mathrm{~cm}^{-1}$, were considered in the scope of the present work. For the 900$940 \mathrm{~cm}^{-1}$ and $650-685 \mathrm{~cm}^{-1}$ spectral regions, the Raman spectrum of pure TPa shows the presence of a small intensity band in the region ascribed to the TPh bands (bands marked with a asterisk (*) in Fig. 4). The presence of these bands could result from a small contamination of the TPa sample with either TPh or a metastable TPm form known to be formed during dehydration at low temperatures (Results and Discussion). However, the comparison of the relative intensities of these bands is not consistent with the presence of any amount of TPh,

Table 3. Results Obtained for the Linear Fitting of the Predicted Relative Concentration as a Function of the Known Molar Fraction of TPh/TPa Physical Mixtures

\begin{tabular}{|c|c|c|c|c|c|c|c|c|}
\hline \multirow[b]{2}{*}{ Spectral Region } & \multicolumn{8}{|c|}{ Band Center $\left(\mathrm{cm}^{-1}\right)$} \\
\hline & $\begin{array}{l}\text { Vibrational } \\
\text { Mode }^{a}\end{array}$ & $\mathrm{TPa}$ & $\mathrm{TPh}$ & $b^{b}$ & $s_{\mathrm{b}}^{b}$ & $a^{b}$ & $R^{2 b}$ & $\delta_{\mathrm{TPa}} / \delta_{\mathrm{TPh}}^{b}$ \\
\hline $3060-3160 \mathrm{~cm}^{-1}$ & $\nu_{\mathrm{C}_{8}-\mathrm{H}}$ & 3123 & 3109 & 1.0075 & 0.04 & 0.0002 & 0.99 & 0.5 \\
\hline $1300-1340 \mathrm{~cm}^{-1 c}$ & $v_{\mathrm{CC}}+v_{\mathrm{CN}}$ & 1315 & 1322 & 0.8286 & 0.03 & -0.0077 & 0.99 & 0.3 \\
\hline $900-940 \mathrm{~cm}^{-1}$ & $\alpha_{\text {imidazole }}$ & 928 & 918 & 0.9829 & 0.03 & -0.0137 & 0.99 & 0.3 \\
\hline $650-685 \mathrm{~cm}^{-1}$ & $\alpha_{\text {pyrimidine }}$ & 668 & 674 & 0.9504 & 0.03 & -0.0109 & 0.99 & 0.5 \\
\hline $510-600 \mathrm{~cm}^{-1 c}$ & $\alpha_{\text {pyrimidine }}$ & 555 & 572 & 0.9067 & 0.03 & -0.0051 & 0.99 & 0.6 \\
\hline
\end{tabular}

\footnotetext{
${ }^{a}$ In accordance with Reference ${ }^{65} ; v$ and $\alpha$ stand for stretching and deformation, respectively.
${ }^{b} b, s_{\mathrm{b}}$, and a stand for slope, slope standard deviation and $y$-intercept of the linear regression line, respectively; $R^{2}$ for the correlation coefficient; $\delta_{\mathrm{TPh}}$ and $\delta_{\mathrm{TPa}}$ stand for intrinsic intensities of the mode for the TPh and TPa forms, respectively.

${ }^{c}$ In this spectral regions a third band had to be considered in the deconvolution procedure to account for the asymmetry of the overall band profile (band centers at $1310 \mathrm{~cm}^{-1}$ and at $581 \mathrm{~cm}^{-1}$ ).
} 
and hence they are ascribed to the TPm form. It should be mentioned that the linear fits presented in Table 3 improve when the intensity of these bands is subtracted from the total TPh intensity.

Table 3 also presents the fitting results for two other spectral regions $\left(510-600 \mathrm{~cm}^{-1}\right.$ and $1300-$ $1340 \mathrm{~cm}^{-1}$ ) as they can be used if necessary (namely in studies involving mixtures with excipients, for instance) with some caution. In fact, the deconvolution of these spectral regions were found to require more than two band centers (Tab. 3).

The remaining spectral regions marked in Figure 3 either do not present a single isosbestic point or include Raman bands ascribed to Fermi resonance modes, ${ }^{65}$ and thus preclude a kinetic analysis.

\section{ACKNOWLEDGMENTS}

The authors acknowledge financial support from the Portuguese Foundation for Science and Technology (FCT)_Unidade de Química-Física Molecular and Laboratório Associado CICECO. $\mathrm{MN}$ also acknowledges FCT for a Ph.D. grantSFRH/BD/18854/2004.

\section{REFERENCES}

1. Snider DA, Addicks W, Qwens W. 2004. Polymorphism in generic drug product development. Adv Drug Del Rev 56:391-395.

2. Bauer J, Spanton S, Henry R, Quick J, Dziki W, Porter W, Morris J. 2001. Ritonavir: An extraordinary example of conformational polymorphism. Pharm Res 18:859-866.

3. Chemburker SR, Bauer J, Deming K, Spiwek H, Patel K, Morris J, Henry R, Spanton S, Dziki W, Porter W, Quick J, Bauer P, Donaubauer J, Narayanan BA, Soldani M, Riley D, McFarland K. 2000 . Dealing with the impact of ritonavir polymorphs on the late stage of bulk drug process development. Org Proc Res Dev 4:413-417.

4. Huang L-F, Tong W-Q. 2004. Impact of solid state properties on the developability assessment of drug candidates. Adv Drug Del Rev 56:321-334.

5. Nogrady Th, Weaver DF. 2005. Basic Principles of drug Design I-Drug molecules: Structure and properties. In: Nogrady Th, editor. Medicinal chemistry: A molecular and biochemical approach. New York: Oxford University Press: pp 31-32.

6. Stahl HP. 1980. The problem of drug interactions with excipients. In: Braimer DD, editor. Towards better safety of drugs and pharmaceutical products. New York: Elsevier/North-Holland: pp 265-280.
7. Hu T-C, Wang S-L, Chen T-F, Lin S-Y. 2002. Hydration-induced proton transfer in the solid state of norfloxacin. J Pharm Sci 91:1351-1357.

8. Khankari RK, Grant DJW. 1995. Pharmaceutical hydrates. Thermochim Acta 248:61-79.

9. Fini G. 2004. Applications of Raman spectroscopy to pharmacy. J Raman Spectrosc 35:335-337.

10. Szelagiewicz M, Marcolli C, Cianferani S, Hard AP, Vit A, Burkhard A, von Raumer M, Hofmeier UC, Zilian A, Francotte E, Schenker R. 1999. In situ characterization of polymorphic forms the potential of Raman techniques. J Therm Anal Calorim 57: 23-43.

11. Brittain HG. 1997. Spectral methods for the characterization of polymorphs and solvates. J Pharm Sci 86:405-412.

12. Bugay DE. 2001. Characterization of the solidstate: Spectroscopic techniques. Adv Drug Del Rev 48:43-65.

13. O'Brian LE, Timmins P, Williams AC, York P. 2004. Use of in situ FT-Raman spectroscopy to study the kinetics of the transformation of carbamazepine polymorphs. J Pharm Biomed Anal 36:335-340.

14. Pratini D, Fawcett JP, Gordon KC, Rades T. 2002. Quantitative analysis of polymorphic mixtures of ratinidine hydrochloride by Raman spectroscopy and principal components analysis. Eur J Pharm Biopharm 54:337-341.

15. Gamberini MC, Baraldi C, Tinti A, Rustichelli C, Feriolo V, Gamberini G. 2006. Solid state characterization of chloramphenicol palmitate Raman spectroscopy applied to pharmaceutical polymorphs. J Mol Struct 785:216-224.

16. Starbuck C, Spartalis A, Wai L, Wang J, Fernandez P, Lindemann CM, Zhou GX, Ge Z. 2002. Process optimization of a complex pharmaceutical polymorphic system via in situ Raman spectroscopy. Cystal Growth Des 2:515-522.

17. Hausmann DS, Cambron RT, Sakr A. 2005. Application of on-line Raman spectroscopy for characterizing relationships between drug hydration state and tablet physical stability. Int J Pharm 299:19-33.

18. Amado AM, Flor F, Félix V, Gil AM, Ribeiro-Claro PJA. 2002. Structural studies of solid carbohydrates: The effect of relative humidity on the structure of glucose. Proceedings of the II Iberian Carbohydrate Meeting (II-IBER-CARB) Ronda Málaga Spain, p 171.

19. Ahlqvist MUA, Taylor LS. 2002. Water diffusion in hydrated crystalline and amorphous sugars monitored using H/D exchange. J Pharm Sci 91:690698.

20. Amado AM, Ribeiro-Claro PJA. 1997. H/D and D/H exchange rates in $\alpha$-cyclodextrin and $\alpha$-cyclodextrin inclusion complexes: Raman spectroscopic study. J Chem Soc Faraday Trans 93:2387-2390. 
21. Steiner T, Moreira da Silva AM, Teixeira-Dias JJC, Müller J, Saenger W. 1995. Rapid water diffusion in a cage-type crystal lattice: $\beta$-cyclodextrin dodecahydrate. Angew Chem Int Ed Engl 34:14521453.

22. Moreira da Silva AM, Steiner T, Saenger W, Empis J, Teixeira-Dias JJC. 1996. Dynamics of hydration and dehydration processes of $\beta$-cyclodextrin monitored in real time by Raman spectroscopy. Chem Commun 1871-1872.

23. Moreira da Silva AM, Steiner T, Saenger W, Empis J, Teixeira-Dias JJC. 1997. Dynamics of H/D and D/ $\mathrm{H}$ exchanges in $\beta$-cyclodextrin dodecahydrate observed in real time: Effects from zero-point vibrational energy. Chem Commun 465-466.

24. Moreira da Silva AM, Empis JMA, Teixeira-Dias JJC. 2002. Inclusion of carvone enantiomers in cyclomaltoheptaose ( $\beta$-cyclodextrin): Thermal behaviour and $\mathrm{H} \rightarrow \mathrm{D}$ and $\mathrm{D} \rightarrow \mathrm{H}$ exchange. Carbohydr Res 337:2501-2504.

25. Ahlqvist MUA, Taylor LS. 2002. Water dynamics in channel hydrates investigated using H/D exchange. Int J Pharm 241:253-261.

26. Jørgensen A, Rautanen J, Karjalainen M, Khriachtchev L, Räsänen E, Yliruusi J. 2002. Hydrate formation during wet granulation studied by spectroscopic methods and multivariate analysis. Pharm Res 19:1285-1291.

27. Taylor LS, Lamgkilde FW. 2000. Evaluation of solid-state forms present in tablets by Raman spectroscopy. J Pharm Sci 89:1342-1353.

28. Salameh AK, Taylor LS. 2006. Physical stability of crystal hydrates and their anhydrates in the presence of excipients. J Pharm Sci 95:446-461.

29. Johnson CE, VanDekoppel S, Myers E. 2005. Stability of anhydrous theophylline in extremporaneously prepared alcohol-free oral suspensions. Am J Health Syst Pharm 62:2518-2520.

30. Benoehr P, Krueth P, Bokemeyer C, Grenz A, Osswald H, Hartmann JT. 2005. Nephroprotection by theophylline in patients with cisplatin chemotherapy: A randomized single-blinded placebocontrolled trial. J Am Chem Soc 16:452-458.

31. Mueller C. 2004. Prevention of contrast nephropathy in critically ill patients using acetylcysteine and theophylline. Int J Art Org 27:1066-1069.

32. Kasim NA, Whitehouse M, Ramachandran C, Bermejo M, Lennarnäs H, Hussain AS, Junginger HE, Stavchansky SA, Midha KK, Shah VP, Amidon GL. 2004. Molecular properties of WHO essential drugs and provisional biopharmaceutical classification. Mol Pharm 1:85-96.

33. Debnath S, Suryanarayanan R. 2004. Influence of processing-induced phase transformations on the dissolution of theophylline tablets. AAPS Pharm Sci Tech 5:article 8.

34. Negro S, Herrero-Vanrell R, Barcia E, Villegas S. 2001. Comparative study of the dissolution profiles of a commercial theophylline product alter storage. Arch Pharm Res 24:568-571.

35. Phadnis NV, Suryanarayanan R. 1997. Polymorphism in anhydrous theophylline-implications on the dissolution rate of theophylline tablets. J Pharm Sci 86:1256-1263.

36. Airaksinen S, Karjalainen M, Räsänen E, Rantanen J, Yliruusi J. 2004. Comparison of the effects of two drying methods on polymorphism of theophylline. Int J Pharm 276:129-141.

37. Karjalainen M, Airaksinen S, Rantanen J, Aaaltonen J, Yliruusi J. 2005. Characterization of polymorphic solid-state changes using variable temperature X-ray powder diffraction. J Pharm Biomed Anal 39:27-32.

38. Suihko E, Lehto V-P, Ketolainen J, Laine E, Paronen P. 2001. Dynamic solid-state and tableting properties of four theophylline forms. Int J Pharm 217:225-226.

39. Ebisuzaki Y, Boyle PD, Smith JA. 1997. Methylxanthines I anhydrous theophylline. Acta Cryst C53:777-779.

40. Sutor DJ. 1958. The structure of the pyrimidines and purins VI the crystal structure of theophylline. Acta Cryst 11:83-87.

41. Sun C, Zhou D, Grant DJW, Young VG, Jr. 2002. Theophylline monohydrate. Acta Cryst E58:368370.

42. Ribeiro-Claro PJA, Amado AM. 2005. Comment on vibrational spectra investigation on xanthine and its derivatives-theophylline caffeine and theobromine. Spectrochim Acta A61:2796-2797.

43. Gunasekaran S, Sankari G, Ponnusamy S. 2005. Vibrational spectral investigation on xanthine and its derivatives - theophylline caffeine and theobromine. Spectrochim Acta A61:117-127.

44. Otsuka M, Kaneniwa N, Kawakami K, Umezawa O. 1990. Effect of surface characteristics of theophylline nahydrate powder on hygroscopic stability. J Pharm Pharmacol 42:606-610.

45. Lehto V-P, Laine E. 2000. Simultaneous determination of the heat and the quantity of vapour sorption using a novel microcalorimetric method. Pharm Res 17:701-706.

46. Räsänen E, Rantanen J, Jørgensen A, Karjalainen M, Paakkari T, Yliruusi J. 2001. Novel identification of psudopolymorphic changes of theophylline during wet granulation using near infrared spectroscopy. J Pharm Sci 90:389-396.

47. Ticehurst MD, Storey RA, Watt C. 2002. Application of slurry bridging experiments at controlled water activities to predict the solid-state conversion between anhydrous and hydrated forms using theophylline as a model drug. Int J Pharm 247: $1-10$.

48. Jørgensen A, Rantanen J, Karjalainen M, Khriachtchev L, Räsänen E, Yliruusi J. 2002. Hydrate formation during wet granulation studied by 
spectroscopic methods and multivariate analysis. Pharm Res 19:1285-1291.

49. Vora KL, Buckton G, Clapham D. 2004. The use of dynamic vapour sorption and near-infrared spectrsocopy (DVS-NIR) to study the crystal transitions of theophylline and the report of a new solid-state transition. Eur J Pharm Sci 22:97-105.

50. Wikström H, Marsac PJ, Taylor LS. 2005. In-line monitoring of hydrate formation during wet granulation using Raman spectroscopy. J Pharm Sci 94:209-219.

51. Agbada CO, York P. 1994. Dehydration of theophylline monohydrate powder-effects of particle size and sample weight. Int J Pharm 106:33-40.

52. Duddu SP, Das NG, Kelly TP, Sokoloski TD. 1995. Microcalorimetric investigation of phase transitions: I is water desorption from theophylline HOH a single-step process? Int J Pharm 114:247256.

53. Shefter E, Fung H-L, Mok O. 1973. Dehydration of crystalline theophylline monohydrate and ampicillin trihydrate. J Pharm Sci 62:791-794.

54. Suihko E, Ketolainen J, Poso A, Ahlgren M, Gynther J, Paronen P. 1997. Dehydration of theophylline monohydrate-a two step process. Int J Pharm 158:47-55.

55. Ledwidge MT, Corrigan OI. 1997. Effects of environmental factors on the dehydration of diclofenac HEP dehydrate and theophylline monohydrate. Int J Pharm 147:41-49.

56. Ono M, Tozuka Y, Oguchi T, Yamamoto K. 2001. Effects of dehydration temperatures on moisture absorption and dissolution behaviour of theophylline. Chem Pharm Bull 49:1526-1530.

57. Otsuka M, Kaneniwa N, Kawakami K, Umezawa O. 1991. Effects of tabletting pressure on hydration kinetics of theophylline anhydrate tablets. J Pharm Pharmacol 43:226-231.

58. Otsuka M, Kaneniwa N, Otsuka K, Kawakami K, Umezawa O, Matsuda Y. 1992. Effect of geometrical factors on hydration kinetics of theophylline anhydrate tablets. J Pharm Sci 81:1189-1193.

59. Ando H, Ishii M, Kayano M, Ozawa H. 1992. Effect of moisture on crystallization of theophylline in tablets. Drug Dev Ind Pharm 18:453-467.

60. Adeyeye CM, Rowley J, Madu D, Javadi M, Sabnis SS. 1995. Evaluation of crystallity and drug release stability of directly compressed theophylline hydrophilic matrix tablets stored under varied moisture conditions. Int J Pharm 116:65-75.

61. Wu C, McGinity JW. 2000. Influence of relative humidity on the mechanical and drug release properties of theophylline pellets coated with an acrylic polymer containing methylparaben as a non-traditional plasticizer. Eur J Pharm Biopharm 50:277-284.
62. Airaksinen S, Luukkonen P, Jørgensen A, Karjalainen M, Rantanen J, Yliruusi J. 2003. Effects of excipients on hydrate formation in wet masses containing theophylline. J Pharm Sci 92:516528.

63. Jørgensen AC, Airaksinen S, Karjalainen M, Luukkonen P, Rantanen J, Yliruusi J. 2004. Role of excipients in hydrate formation kinetics of theophylline in wet masses studied by nearinfrared spectroscopy. Eur J Pharm Sci 23:99104.

64. Vendruscolo CW, Andreazza IF, Ganter JLMS, Ferrero C, Bresolin TMB. 2005. Xanthan and galactomannan (from M scabrella) matrix tablets for oral controlled delivery of theophylline. Int $\mathrm{J}$ Pharm 296:1-11.

65. Nolasco MM, Amado AM, Ribeiro-Claro PJA. 2006. Computationally-assisted approach to the vibrational spectra of molecular crystals: Study of hydrogen-bonding and pseudo-polymorphism. Chem Phys Chem 7:2150-2161.

66. Girling RB, Shurvell HFA. 1998. Raman spectroscopic study of complex formation between o-cresol and propionitrile. Vib Spectr 18:77-82.

67. Brown ME, Galwey AK. 1979. The distinguishability of selected kinetic models for isothermal solid-state reactions. Thermochim Acta 29:129146.

68. Vyazovkin S. 1997. Evaluation of activation energy of thermally stimulated solid-state reactions under arbitrary variation of temperature. J Comp Chem 18:393-402.

69. Ortega A. 2002. The kinetics of solid-state reactions toward consensus Part 3 searching for consistent kinetic results: SCTA vs conventional thermal analysis. Int $\mathrm{J}$ Chem Kinet 34:223-236.

70. Zhu H, Yuen C, Grant DJW. 1996. Influence of water activity in organic solvent+water mixtures on the nature of the crystallizing drug phase 1 theophylline. Int J Pharm 135:151-160.

71. Weast RC, Astle MJ, Beyer WH, Editors CRC Handbook of Chemistry and Physics a ReadyReference Book of Chemical and Physical Data. 64th edn 1983. Florida USA: CRC Press Inc, $\mathrm{p}$ E42.

72. Marigheto NA, Kemsley EK, Potter J, Belton PS, Wilson RH. 1996. Effects of sample heating in FTRaman spectra of biological materials. Spectrochim Acta A52:1571-1579.

73. Johansson J, Pettersson S, Taylor LS. 2002. Infrared imaging of laser-induced heating during Raman spectroscopy of pharmaceutical solids. J Pharm Biomed Anal 30:1223-1231.

74. Davis WH, Jr Pryor WA. 1976. Measures of goodness of fit in linear free energy relationships. J Chem Ed 53:285-287. 